\title{
Influence of Storage Temperature on the Corrosion Behavior of Tinplate in Citric Acid Solution
}

\author{
Jihui Wang ${ }^{1,2, *}$, Li Zhang ${ }^{1,2}$, Yun Gao ${ }^{2}$, Xin Liu' ${ }^{2}$,Wenbin $\mathrm{Hu}^{2}$ \\ ${ }^{1}$ State Key Laboratory of Hydraulic Engineering Simulation and Safety, Tianjin University, Tianjin \\ 300350, P R China \\ ${ }^{2}$ Tianjin Key Laboratory of Composite and Functional Materials, School of Materials Science and \\ Engineering, Tianjin University, Tianjin 300350, P R China \\ *E-mail: jhwang@tju.edu.cn
}

doi: $10.20964 / 2019.01 .24$

Received: 6 August 2018 / Accepted: 4 October 2018 / Published: 30 November 2018

\begin{abstract}
The influence of storage temperature on the corrosion behavior of tinplate was investigated in $0.1 \mathrm{~mol} / \mathrm{L}$ citric acid solution by using immersion test, polarization curve and electrochemical impedance spectroscopy (EIS). The surface morphology of tinplate before and after corrosion was characterized by scanning electron microscopy (SEM), and the dissolution content of iron and tin ions in citric acid solution was determined by inductively coupled plasma mass spectrometer (ICP-MS). The experimental results show that with the increasing of storage temperature the corrosion potential of tinplate in citric acid solution is shifted negatively whereas the corrosion current density is increased obviously. EIS spectrum of tinplate in citric acid solution is transferred from two time constants at the initial immersion into one time constant with the prolonging of immersion time, and the radius of capacitive arc is decreased with the increasing of storage temperature. Meanwhile, the dissolution rate of tin and iron in citric acid is also promoted by storage temperature. Finally the corrosion mechanism of tinplate in citric acid solution is proposed and discussed, and the activation energy is calculated and correlated with the corrosion process of tinplate.
\end{abstract}

Keywords: storage temperature; tinplate; citric acid; corrosion behavior; EIS spectrum

\section{$\underline{\text { FULL TEXT }}$}

(C) 2019 The Authors. Published by ESG (www.electrochemsci.org). This article is an open access article distributed under the terms and conditions of the Creative Commons Attribution license (http://creativecommons.org/licenses/by/4.0/). 